\title{
DETERMINATION OF BPSG THIN-FILM PROPERTIES USING IR REFLECTION SPECTROSCOPY OF PRODUCT WAFERS
}

\author{
THOMAS M. NIEMCZYK*, JAMES E. FRANKE*, LIZHONG ZHANG*, \\ DAVID M. HAALAND ${ }^{* *}$, and KENNETH J. RADIGAN ${ }^{* * *}$ \\ "Chemistry Department, University of New Mexico, Albuquerque, NM 87131 \\ ${ }^{* *}$ Sandia National Laboratories, Albuquerque, NM 87185 \\ ${ }^{* * *}$ National Semiconductor, Santa Clara, CA 95052
}

\begin{abstract}
Three BPSG calibration sets were analyzed using infrared external reflection-absorption spectroscopy: 1) 21 films deposited on undoped silicon coated with $0.1 \mu \mathrm{m}$ of silicon dioxide, 2) 21 films deposited on undoped silicon, and 3) 9 films deposited on microelectronics product wafers. A multivariate partial least squares analysis of the spectral data for the first large data set showed that boron content, phosphorus content, and film thickness can be quantified with precisions of 0.10 $\mathrm{wt} \%, 0.12 \mathrm{wt} \%$, and $30 \AA$, respectively. The second large data set yielded similar results. The precisions obtained for the nine product wafer samples were $0.13 \mathrm{wt} \% \mathrm{~B}, 0.09 \mathrm{wt} \% \mathrm{P}$, and for film thickness $103 \AA$.
\end{abstract}

\section{INTRODUCTION}

Borophosphosilicate glass (BPSG) thin films are widely used in the microelectronics industry as passivation layers, planarization layers, low-fusion-temperature dielectrics, etc. ${ }^{1}$ Currently available analytical methods for determining boron and phosphorus content in BPSG films do not meet the demands of at-line or in-situ quality control process monitoring. Infrared (IR) spectroscopy satisfies many of the at-line or in-situ issues, but has only recently been capable of providing quantitative results using undoped and unpatterned silicon substrates ${ }^{2-4}$. For a review on the use of quantitative IR methods for dielectric thin film analysis, see ref. [2]. A quantitative IR analysis of dielectric thin films deposited on doped and patterned silicon wafers, which are used in fabricating actual microelectronics product wafers, has not previously been reported, primarily due to the fact that doped silicon is not IR-transparent. Thus, any IR technique used fo: monitoring the production of BPSG thin films on actual product wafers cannot involve IR transmission. IR external reflectionabsorption spectroscopy (IRRAS) is one technique that can satisfy the requirements for quality control of BPSG thin films on product wafers. In this study, we use IRRAS and partial least-squares multivariate calibration for quantitative and simultaneous determination of boron content, phosphorus content, and film thickness in BPSG thin films deposited on both undoped/unpatterned and doped/patterned silicon wafers.

\section{EXPERIMENTAL}

Two 21-sample BPSG calibration sets were prepared on $150 \mathrm{~mm}$ silicon wafers using a TEOS-BPSG process at a deposition temperature of $430^{\circ} \mathrm{C}$. One set was deposited on uncoated, undoped, and unpatterned silicon (monitor) wafers and the other was deposited on monitor wafers previously coated with $0.10 \mu \mathrm{m}$ of silicon dioxide (oxide-coated monitor wafers). The BPSG films

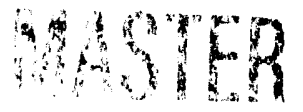

$d i^{2}$ 
were then annealed at $800^{\circ} \mathrm{C}$ in steam for 10 minutes followed by a $900^{\circ} \mathrm{C}$ treatment in nitrogen for 20 minutes. BPSG film thickness in the samples deposited on monitor wafers varied between 0.6711 and $0.8218 \mu \mathrm{m}$, as measured with a Nanospec film thickness analyzer. Boron ranged between 2.80-5.24 wt \% while phosphorus spanned 3.17-5.25 wt \%, based on quantitative wet chemical analyses (Balazs Laboratories, Sunnyvale, CA) of half-wafers from the set deposited on monitor wafers. The reported precisions of the reference methods for both $\mathrm{B}$ and $\mathrm{P}$ content were reported as $\leq 0.1 \mathrm{wt} \%$. The precision of the film thickness measurement was reported as $\pm 30 \AA$, which was the standard deviation of five measurements taken within a $1-\mathrm{cm}$ pattern centered on the wafer. The sister set of BPSG samples deposited on oxide-coated monitor wafers were assumed to possess the same values for $\mathrm{B}, \mathrm{P}$, and film thickness as described for corresponding samples in the monitor wafer set. Using the same TEOS-BPSG process described earlier, nine BPSG samples were deposited on doped and patterned silicon (product) wafers. These product wafer samples were produced with a proprietary $0.65 \mu \mathrm{m}$ CMOS process and then coated with BPSG thin-films having 3.0-5.2 wt \% B, 3.2-5.3 wt \% P, and 0.67-0.79 $\mu \mathrm{m}$ film thickness. These nine samples each possessed a sister wafer in the monitor wafer calibration set, so their individual $\mathrm{B}, \mathrm{P}$, and film thickness parameters were presumed to be the same as the corresponding sister samples in the monitor set.

IRRAS spectra were obtained using a Nicolet 800 FTIR spectrophotometer equipped with a DTGS (deuterium triglycine sulfate) detector. Spectra were obtained by averaging $324 \mathrm{~cm}^{-1}$ resolution scans. BPSG samples were held in a modified Harrick reflection accessory at $25^{\circ}$ incidence (relative to wafer surface normal). Each sample spectrum was ratioed to a background spectrum obtained from a gold mirror to produce the appropriate reflectance $\left(R / R_{0}\right)$ spectrum. The spectral data are reported as $-\log \left(R / R_{0}\right)$ versus frequency. Multivariate analysis was perfo med on the $-\log \left(R / R_{0}\right)$ data using the particular partial least-squares (PLS) algorithm that calibrates and predicts each component property separately from the same spectral data (PLS1). The PLS1 algorithm has been described in detail elsewhere ${ }^{5}$

\section{RESULTS AND DISCUSSION}

Figure 1 shows the IRRAS spectra of the 21 BPSG samples deposited on oxide-coated monitor wafers. The features of these types of spectra, including absorption band assignments and optical effects, have been described ${ }^{3,4}$. Briefly, boron information is primarily observed in the B-O

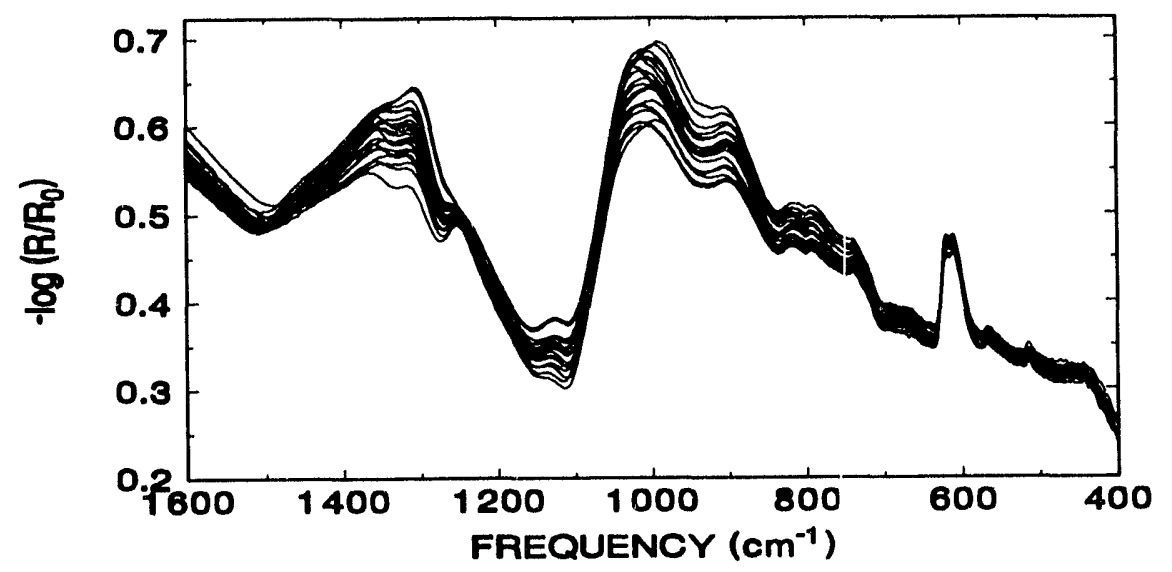

Figure 1. IRRAS spectra at $25^{\circ}$ of $21 \mathrm{BPSG}$ thin films on oxide-coated monitor wafers. 
band (1300-1500 $\mathrm{cm}^{-1}$ ) and the B-O-Si band (ca. $900 \mathrm{~cm}^{-1}$ ), and phosphorus information is primarily observed in the $\mathrm{P}=\mathrm{O}$ band (shoulder at ca. $1310 \mathrm{~cm}^{-1}$ ) that is highly overlapped with the $\mathrm{B}-\mathrm{O}$ band. Information regarding the film thickness is primarily contained in the strongly absorbing Si-O band centered at about $1100 \mathrm{~cm}^{-1}$ in IR transmission spectra. This band appears as a pseudo first derivative feature $\left(1000-1150 \mathrm{~cm}^{-1}\right)$ in the IRRAS spectra of Fig. 1 due to thin film $\mathrm{c}$ tical effects. The pseudo first derivative structures present in IRRAS spectra of thin films ar examples of noniinear spectral behavior that can significantly increase the difficulty of achieving 1 quantitative analysis based on the spectral data. In such a situation, adequate quantitative results generally depend on the use of a multivariate calibration.

Figure 2 details the results of predicting boron content from the BPSG IRRAS spectra in Figure 1, using a PLS1 calibration model. The calibration procedure for boron consisted of taking the first derivative of the spectral data between 890 and $1600 \mathrm{~cm}^{-1}$ and dividing the spectral intensities by the film thickness for a given sample prior to application of the PLS1 algorithm. The combined model error, bias, and experimental error are described by the standard error of prediction (cross-validated) statistic ${ }^{4}$, denoted SEP(CV). The line through the 21 points in Fig. 2 represents the least-squares fit to the data. The SEP(CV) value for boron in Fig. $2(0.10 \mathrm{wt} \%)$ is based on the

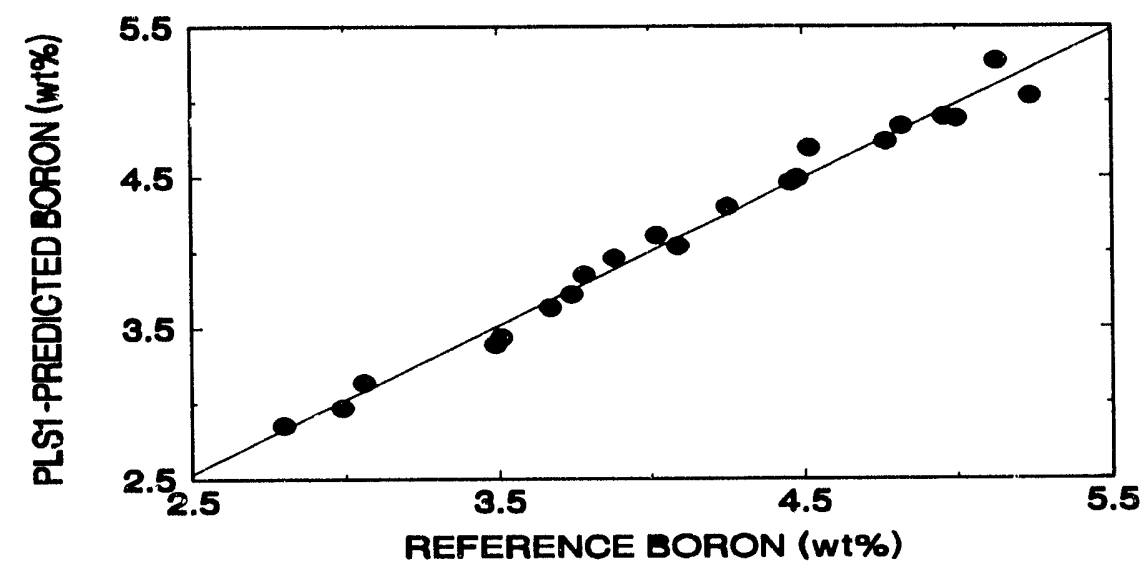

Figure 2. PLS1-prediction of boron in BPSG films from the IRRAS spectral data in Fig. 1.

difference between the cross-validated, PLS1-predicted boron values and reference-method boron values. It is germane to note that this $\operatorname{SEP}(\mathrm{CV})$ for boron is equivalent to the reported precision of the reference method for boron determination $(\leq 0.1 \mathrm{wt} \%)$. The SEP $(\mathrm{CV})$ plots for phosphorus and film thickness appear similar to Fig. 2, with SEP(CV) for $\mathrm{P}$ of $0.12 \mathrm{wt} \%$ and for film thickness of $30 \AA$. The SEP(CV) for $P$ is similar to the precision of the reference method $(\leq 0.1 \mathrm{wt} \%)$, and the $\mathrm{SEP}(\mathrm{CV})$ for film thickness is equivalent to the variation of film uniformity and instrument error $( \pm 30 \AA)$ in a $1-\mathrm{cm}$ pattern centered on the wafer. The PLSI analysis of IRRAS spectra of BPSG films on monitor wafer samples yields similar quantitative results.

1. Figure 3 shows the IRRAS spectra of the nine BPSG samples deposited on product wafer samples. The spectral data in Fig. 3 exhibit features similar to those in the IRRAS spectra of Fig. 1 , with two significant exceptions. The silicon phonon band at $610 \mathrm{~cm}^{-1}$, for example, is absent in Fig. 3. The presence or absence of this band indicates whether or not radiation reaching the detector has passed through the silicon wafer. The presence of the phonon band in Fig. 1 is an indication that 


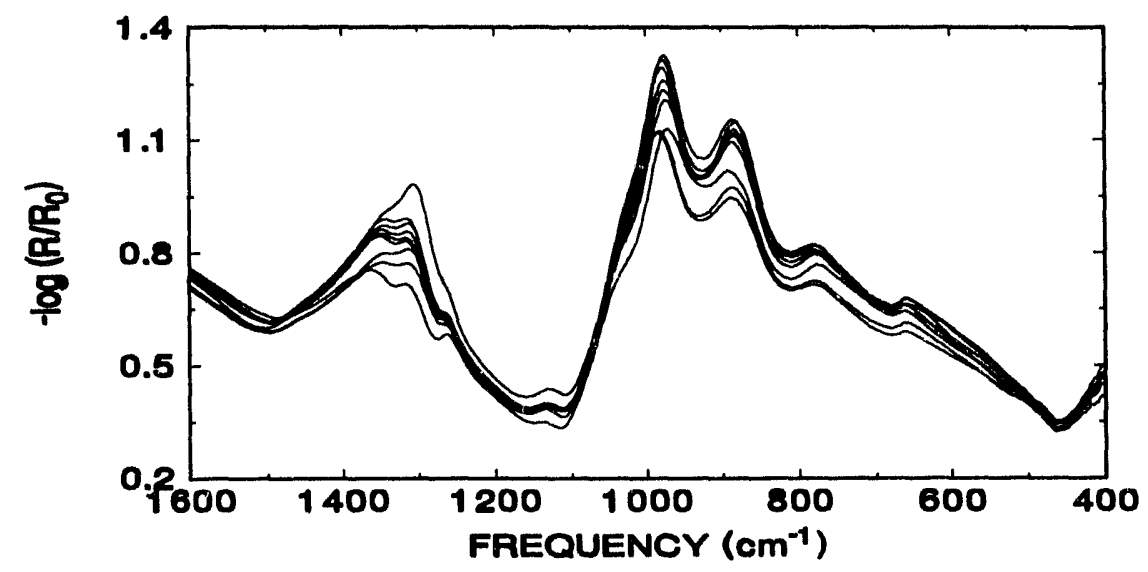

Figure 3. IRRAS spectra at $25^{\circ}$ of nine BPSG thin films deposited on product wafers.

at least some fraction of the radiation reaching the detector is a result of reflection from the backside of the wafer. The absence of the feature in Fig. 3 is an indication that none of the radiation reaching the detector is a result of backside reflection. Another indication of how the different substrates affect the BPSG IRRAS spectra is shown by the approximate doubling of some reflection-absorption signals $\left(-\log \left(R / R_{0}\right)\right)$ in the product wafer spectra (Fig. 3$)$ over the oxide-coated monitor wafer spectra (Fig. 1). This means that less IR radiation reaches the detector in some spectral regions (e.g., 800-1050 and 1250-1450 $\mathrm{cm}^{-1}$ ) of Fig. 3 compared to Fig. 1, probably because the IR absorptivity and reflectivity differ in the two types of substrates. As a result, the major BPSG bands (at about $1370,1320,1000$, and $900 \mathrm{~cm}^{-1}$ ) in the IRRAS spectra of product samples appear larger than those in the IRRAS spectra of the BPSG samples on oxide-coated monitor wafers in Fig. 1. The greater magnitude of the band intensity variations may possibly be related to differences in the refractive index of the two different substrates and/or to the relative magnitudes of the incident IR wavelength $(6-25 \mu \mathrm{m})$ and the pattern feature sizes $(0.65 \mu \mathrm{m})$ in the product wafer samples, but these effects have not been studied. Given the favorable appearance of the IRRAS spectra of product wafers (major BPSG band intensities vary systematically with BPSG property values), a PLS1 calibration of the IRRAS BPSG product wafer spectra was performed.

For comparing the PLSi calibration results of product and oxide-coated monitor BPSG samples, the nine samples in the oxide-coated monitor set that correspond to the nine product wafer samples were selected. PLS1 calibrations were performed on both sets of nine samples, and the results for the boron calibrations are detailed in Figure 4. For the nine oxide-coated monitor BPSG samples, the PLS1 boron calibration model used spectral frequencies between 927 and $1500 \mathrm{~cm}^{-1}$ and preprocessed the spectral data by scaling the spectra for relative dielectric film pathlength and performing a linear baseline correction for all spectra over the 927 to $1500 \mathrm{~cm}^{-1}$ calibration. The PLS1 boron calibration model for the nine BPSG product wafer samples used a calibration range of $455-1500 \mathrm{~cm}^{-1}$ and linear baseline correction for spectral data preprocessing. As shown in Fig. 4 , the boron SEP(CV) value for the nine oxide-coated monitor BPSG samples is $0.11 \mathrm{wt} \%$, while that for the corresponding product samples is $0.13 \mathrm{wt} \%$. For phosphorus determination, the nine oxide-coated monitor BPSG samples produced a SEP(CV) of $0.09 \mathrm{wt} \%$ and the nine product wafers yielded $0.09 \mathrm{wt} \%$ as well. Film thickness was predicted with a SEP(CV) of $120 \AA$ for the oxidecoated monitor samples and $103 \AA$ for product samples. The results for each BPSG component property using nine oxide-coated monitor BPSG samples are not statistically different than the 


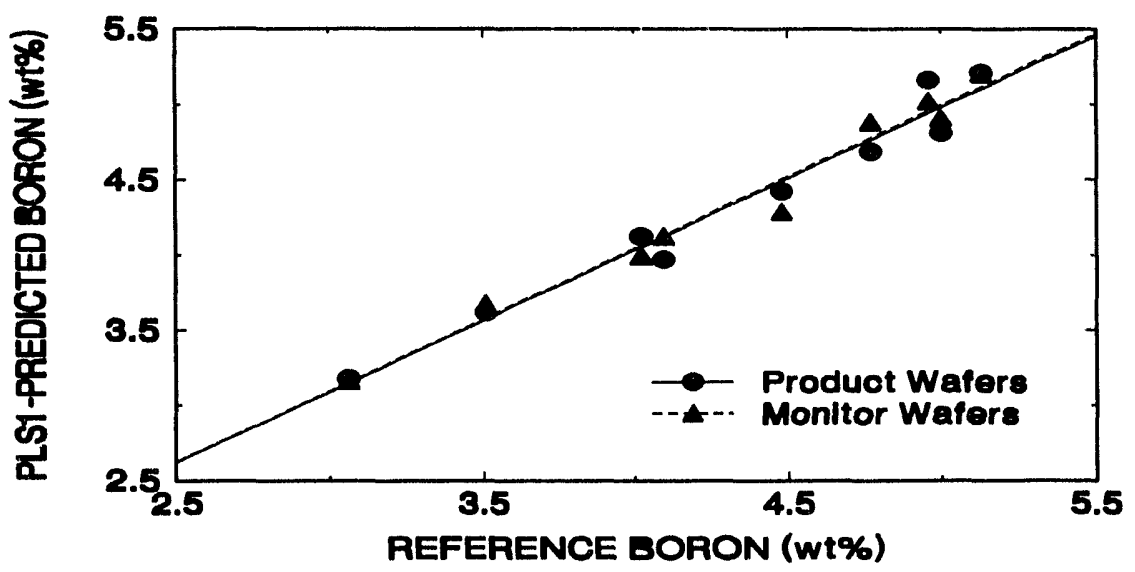

Figure 4. PLS1-prediction of boron in BPSG films from the IRRAS spectral data in Fig. 3 and nine of the spectra in Fig. 1.

results obtained using the nine product BPSG samples. Although these resulis have been obtained with a limited sample set, they suggest that BPSG component concentrations can be calibrated to within the precision of the reference methods for both monitor and product wafers using PLS1 multivariate calibration of BPSG IRRAS spectra.

\section{CONCLUSIONS}

PLS1 multivariate calibration of BPSG IRRAS spectra provides a rapid $(<1 \mathrm{~min}$.), at-line or in-situ, nondestructive, and quantitative process monitor for quality control of BPSG component properties that is especially important to the microelectronics industry. Calibration precision comparable to that of the reference methods used to determine boron, phosphorus, and film thickness can be achieved using BPSG samples deposited on monitor and oxide-coated monitor wafers. Equivalent calibration precision (for B and P) or slightly worse precision (for film thickness) were obtained using a limited number of BPSG thin films deposited on product wafers. However, the calibration results using the nine corresponding BPSG films on oxide-coated monitor wafers showed the same trends in precision as the product samples, suggesting that the slightly worse precision for thickness may be related to the limited sample size. Thus, PLS 1 calibration of BPSG IRRAS spectra is a very promising technique for the characterization of BPSG thin films deposited on product wafers. The availability of such a technique will greatly enhance the quality control of BPSG films used in actual microelectronics devices.

\section{ACKNOWLEDGMENTS}

This work was performed in part at Sandia National Laboratories and was supported by the U.S. Dept. of Energy under Contract Number DE-AC04-94AL85000 and by the Semiconductor Research Corporation/SEMATECH through the University of New Mexico SEMATECH Center of Excellence. 


\section{REFERENCES}

1. W. Kern, W.A. Kurylo, and C.J. Tino, RCA Review, 46, 117-152 (1985).

2. J.E. Franke, T.M. Niemczyk, and D.M. Haaland, Spectrochimica Acta, in press.

3. J.E. Franke, L. Zhang, T.M. Niemczyk, D.M. Haaland, and J.H. Linn, J. Electrochem. Soc., 140(5), 1425 (1993).

4. D.M. Haaland, Anal. Chem., 60, 1208 (1988).

5. D.M. Haaland and E.V. Thomas, Anal. Chem., 60, 1193 (1988).

\section{DISCLAIMER}

This report was prepared as an account of work sponsored by an agency of the United States Government. Neither the United States Government nor any agency thereof, nor any of their employees, makes any warranty, express or implied, or assumes any legal liability or responsibility for the accuracy, completeness, or usefulness of any information, apparatus, product, or process disclosed, or represents that its use would not infringe privately owned rights. Reference herein to any specific commercial product, process, or service by trade name, trademark, manufacturer, or otherwise does not necessarily constitute or imply its endorsement, recommendation, or favoring by the United States Government or any agency thereof. The views and opinions of authors expressed herein do not necessarily state or reflect those of the United States Government or any agency thereor. 

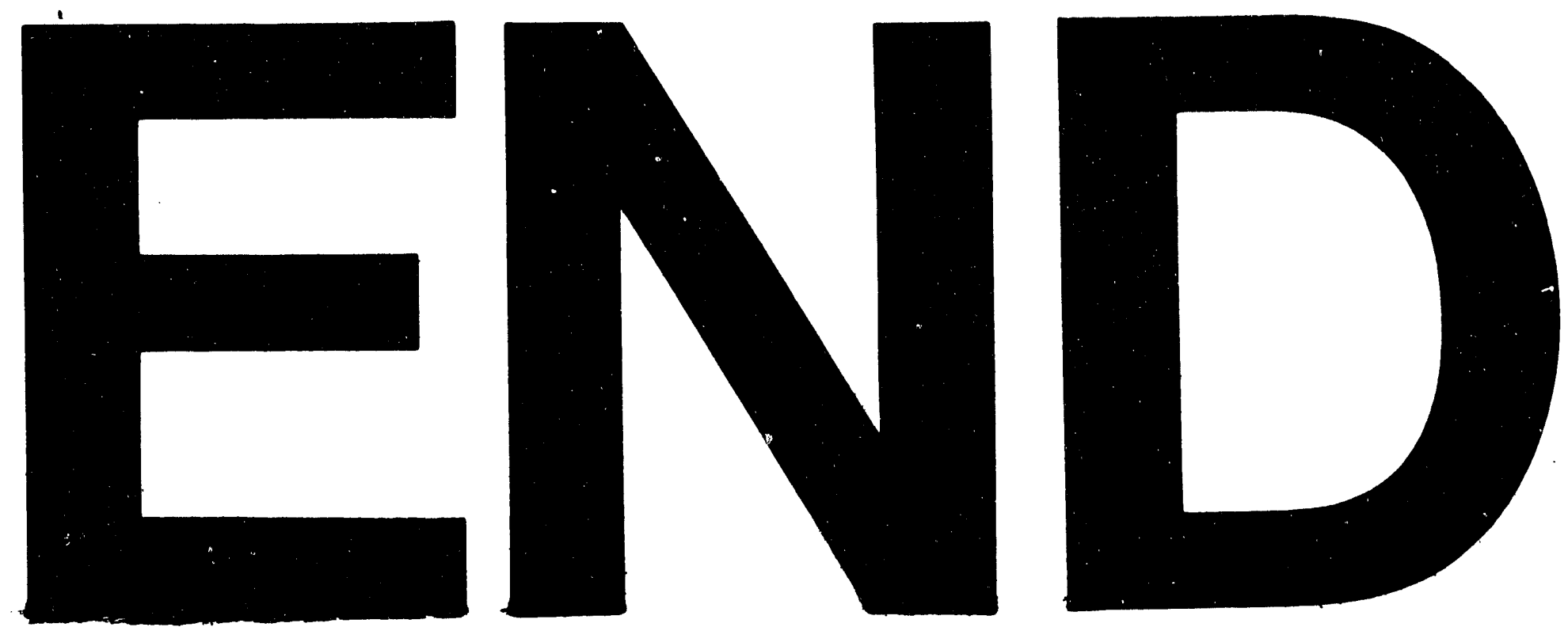

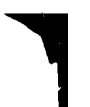
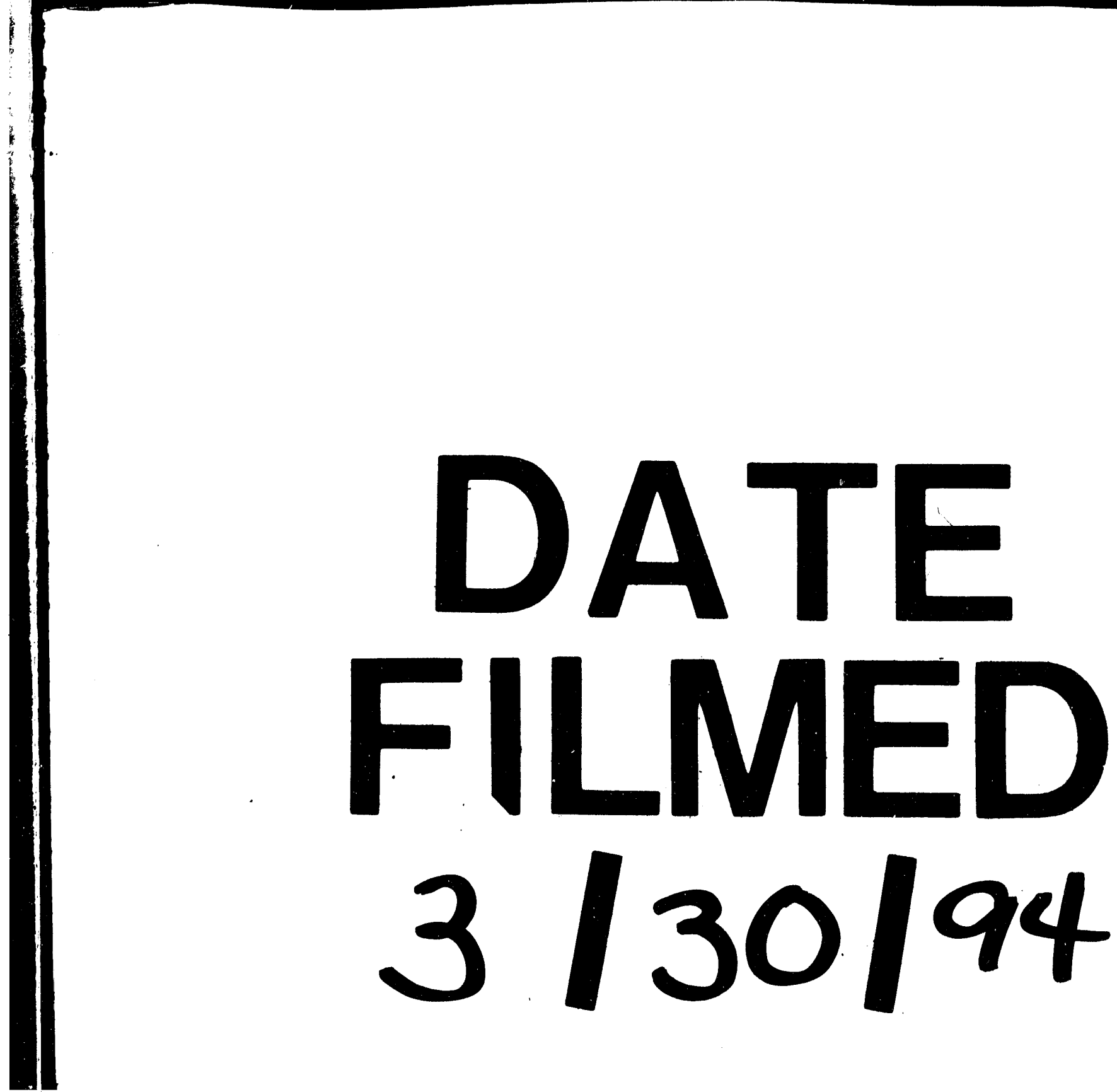


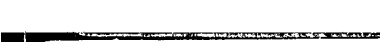

